\title{
INTERACTION OF POWER PLANT WITH AIRFRAME OF NEW GENERATION AIRCRAFT
}

\section{Baklanov}

Tupolev

\author{
17 Tupolev Embankment, Moscow 105005, Russia
}

\begin{abstract}
Strategic development of new generation airplanes goes in the direction of further noise decreasing and increasing fuel efficiency, where the determining role belongs to superhigh bypass ratio engines, especially with application gearbox scheme. Fan shaft components will determine the spectrum of power plant dynamic effect transferred via mounting assembly (engine attachments) on airframe structure. This spectrum is reradiated into the cabin in the form of structural noise. Long-term researches of engines (with different bypass ratio) and airframe have allowed $(i)$ to calculate expected structural noise on the new generation aircraft; and (ii) to offer the concept of new vibration isolation mounting.
\end{abstract}

\section{INTRODUCTION}

High bypass ratio engines were installed at the aircraft 33 years ago.

Over the years, the evolution of the engines towards increasing bypass ratio from high (4.5-6.0) to superhigh (8-12) bypass ratio engines was well-shaped that provides noise abatement of new engines by $10-15 \mathrm{~dB}$.

Application of superhigh bypass engines provides a significant increasing of fuel efficiency that has become a requirement for new generation engines in crisis and high oil prices maintenance.

Servicing of a huge long-haul aircraft park (20000) is required to reduce the engine maintenance costs that cause the trend to pass from 4-engine power plants to 2-engine power plants of larger thrust.

Anyway, there is a tendency of fan diameters to increase while shockwaves tend to be generated at supersonic speed of blade tips.

One of necessary measures of shockwave control is the reduction of fan shaft speed. In this case, to maintain gas generator efficiency, a low-speed low-pressure

This is an Open Access article distributed under the terms of the Creative Commons Attribution License 2.0, which permits unrestricted use, distribution, and reproduction in any medium, provided the original work is properly cited. 


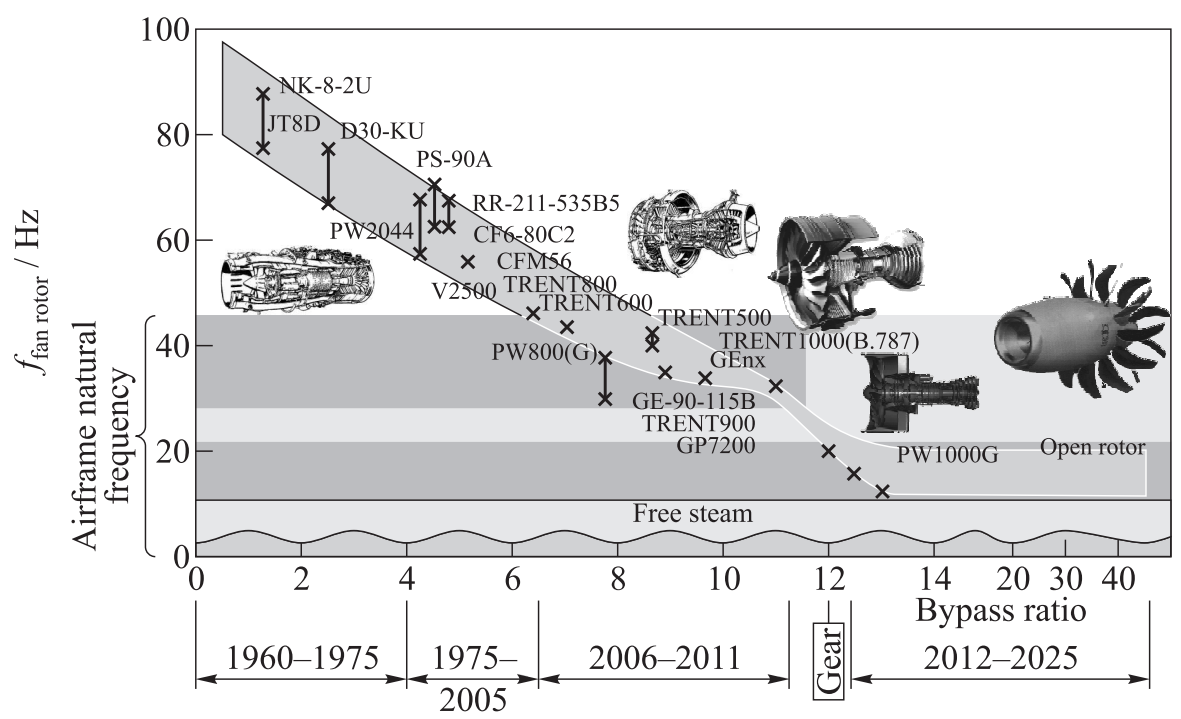

Figure 1 Change of frequency of rotation of fan shaft at degree increase of bypass ratio of engines

turbine should be provided with increased number of stages and blades that increases the engine weight and price.

To keep rotation speed of low-pressure turbine and reduce the number of stages, it is necessary to disconnect fan shafts and turbine using gearbox plant that provides the optimal speed for the fan shaft (lower) and for the turbine (high).

Today, we are on the next stage of engines development - the transition to superhigh bypass engines $(m=10-13)$. It makes turbofan engine similar to turboprop, especially in case of gearbox scheme application and concept of "open rotor."

Due to the decrease of frequency, vibration spectrum shifts towards the low-frequency range. Such components will determine dynamical impact spectrum of power plant, transmitted through mounting to airframe construction (Fig. 1).

Thus, some components of an air-gas path, for example, frequency of a rotary vortex $\left(f=(0.35-0.42) f_{\text {fan rotor }}\right)$ were observed earlier. These components were already in the area of interaction with own frequencies of airframe (control system elements, for example). Interaction of this component with airframe caused formation of a low-frequency component of high level.

Transition to engines superhigh bypass ratio with the fan of big diameter demands essential decrease in speed of fan's shaft that is confirmed by the newest 
engines GE 90-115B $(m=9.0)$ and TREND1000 $(m=11)$ which have the least speed of rotation of the fan $(f=32-35 \mathrm{~Hz})$ nowadays.

\section{SPECTRUMS, SOURCES, AND PATHS PROPAGATION}

Operating experience of new generation engines has shown that substantial noise redistribution occurs. While jet noise has been reduced dramatically, the engine still remains the basic source of noise, but now it is fan noise in both forward and backward hemispheres. In the forward hemisphere, beside the discrete components at fan blade frequency, long row of discrete components has been observed around the principal blade frequencies as result of shockwave influence. This phenomenon is called "buzz-saw noise."

These components are up to $10-25 \mathrm{~dB}$ more intensive than cabin background noise. Fan diameter increasing in high bypass ratio engines, fan blades start rotating at ultrasonic speed, thus generating shockwaves.

With the development of large engines with diameters of 110-120 in and relatively short inlet length, buzz saw noise became an issue over a large segment of the passenger cabin [1].

Studies on the generation of buzz noise have been published by several authors [2-4] since the 1970s, with the introduction of higher bypass ratio aircraft engines.

The pressure signature associated with an ideal fan, consisting of precisely identical rotor blades in a uniform flow, will be a regular sawtooth. The frequency spectrum of a regular sawtooth only contains energy at the Blade Passing Frequency (BPF) harmonics.

In practice, the rotor blades will not be precisely identical: there will be small variations between the blades' profiles, spacings, and stagger angels. Stratford and Newby [5] considered the sources of blade nonuniformities and suggested that the initial variations in shock strength are largely attributable to stagger angle variations.

The frequency spectrum of an irregular sawtooth now contains energy distributed amongst harmonics based on the engine rotation frequency fan.

The shocks is an irregular sawtooth will propagate upstream of the fan at slightly different speeds and by the end of the inlet duct, the dominant energy will now be at Engine Order harmonics whose frequencies are less than BPF. The redistribution of acoustic energy between the Engine Order harmonics occurs during the nonlinear propagation of a high-amplitude irregular sawtooth. Therefore, a lower-pitched more "ragged" noise is generated because of the presence of energy in the low-frequency Engine Order harmonics [6]. 


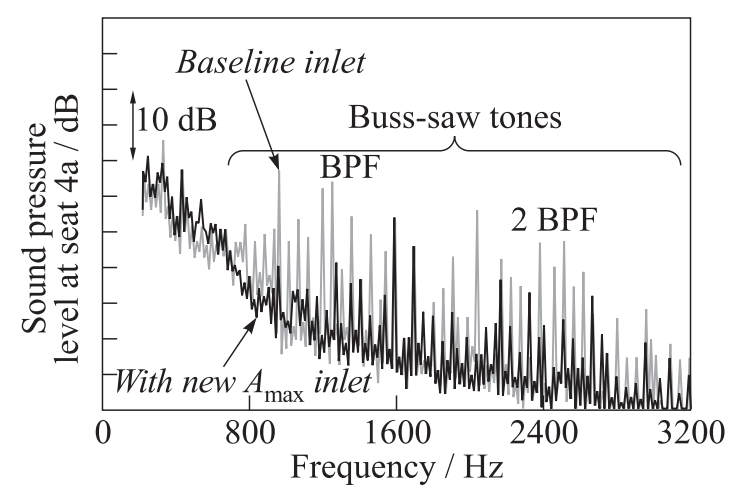

Figure 2 Buzz-saw noise decrease in B-777 cabin (with new $A_{\text {max }}$-inlet) [7]

At the end of the inlet, the rotating system of shocks will be evolved into a highly irregularly spaced pressure pattern that will radiate to the far field or to the fuselage sidewall. The noise that is the frequently heard in the passenger cabin consists of a multitude of buzz-saw noise giving it a very unusual characteristic (Fig. 2).

More than 50 high-frequency harmonics are observed in the cabin within the range $750-3200 \mathrm{~Hz}$. This is a result of underestimating of the fan acoustic emission power of an extrahigh bypass ratio engine when choosing noise isolation of the aircraft side within the front hemisphere of engine inlet.

Buzz-saw noise is one part (high-frequency region) of the spectrum of noise expected in the pressurized cabin of new generation engines with extrahigh bypass ratio. The other part of the spectrum is the low-frequency region which includes rotor frequencies of the three shafts and duct low-frequency components has not been shown in Fig. 2.

Except for irradiation of a board of the planes, the shockwaves interacting with fan wheel generate a wide spectrum of vibrations transferred to engine body via mounting points; the low-frequency part of spectrum (below $500 \mathrm{~Hz}$ ) spreads over the construction as structure-borne noise.

Vibration contribution to the acoustic properties of the pressurized cabin has been determined during the investigations of the vibroisolating engine mount, which was designed taking into account the real dynamic characteristics (engine case and airframe dynamic compliance) [8].

Vibration spectra of engine case for front (Figs. $3 b$ and $3 c$ ) and aft mount location of sensors are presented in Fig. 3. A series of polyharmonic discrete components has been observed in the spectrum of engine case vibrations, especially for the front mount location. These components are grouped around the main blade frequencies (the 1st and the 2nd harmonics), the distance between 


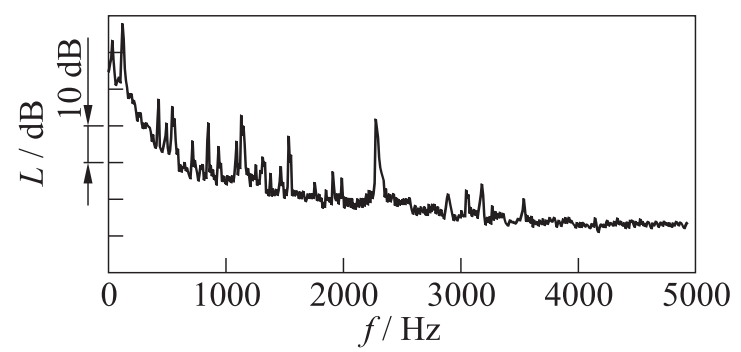

(a)

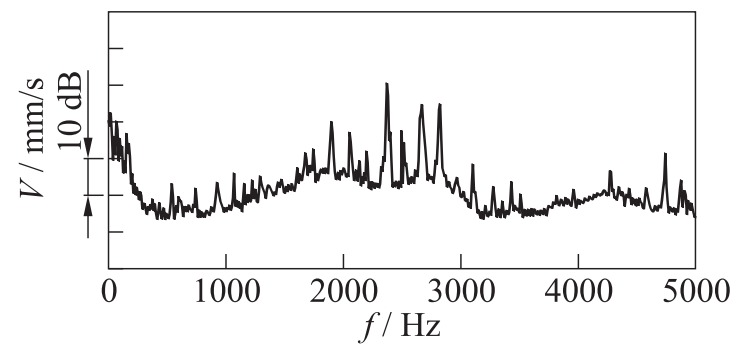

(b)

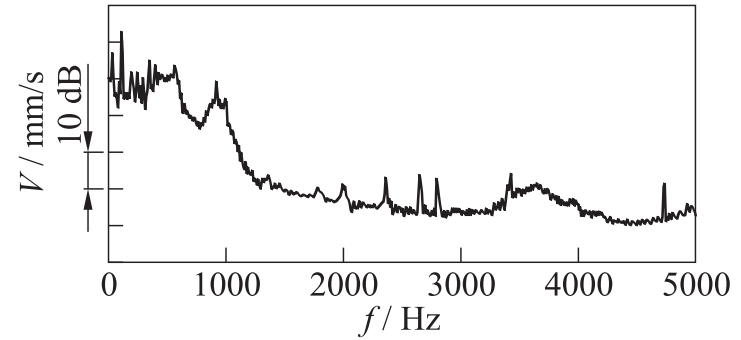

(c)

Figure 3 Noise and vibration spectrums (various location of the sensor): (a) noise spectrum in pressurized cabin (engine mount zone); $(b)$ vibrations spectrum of engine case (front mount); and $(c)$ vibrations spectrum of engine case (aft mount)

the components and blade frequency being equal to shaft rotation frequency. This yields a formula for the position of the corresponding peak in spectrum:

$$
f=\sum_{m=1 \ldots n}^{i} m f_{f}(z \pm i) .
$$

Here, $f$ is the frequency of discrete components; $f_{f}$ is the fan shaft rotation frequency; $z$ is the number of fan blades; $m$ is the number of harmonics at blade frequency, $i=0,1,2, \ldots, k$. 


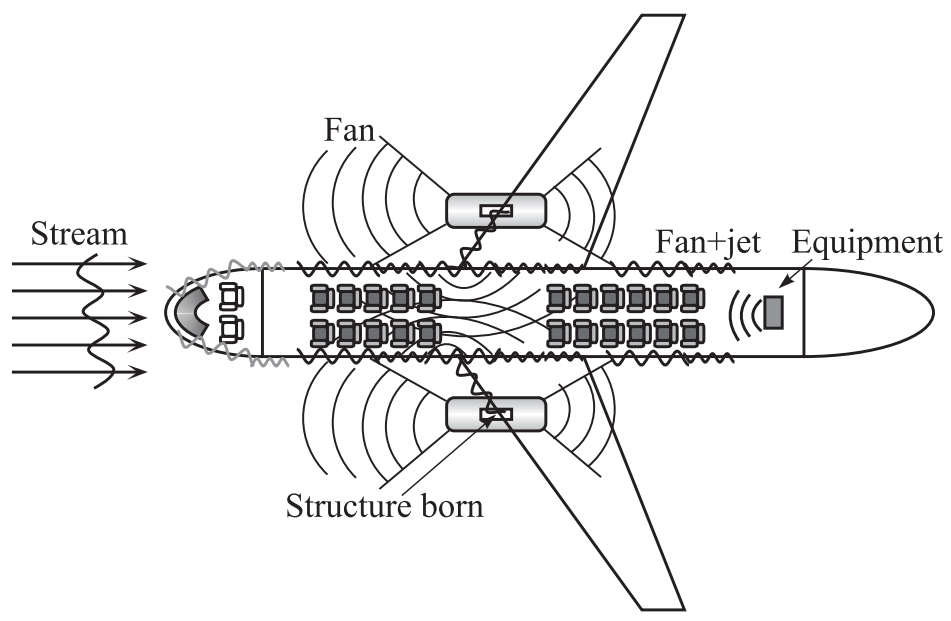

Figure 4 Main noise sources in cabin

All these components of the vibration spectrum, as well as the discrete components of vibration activity devices, installed in the engine (e.g., plunger pump), or the spectral components of new devices (e.g., chevron nozzles, introduced into the stream and supplementing the vibration spectrum of engine case) will be a source of structure-borne noise, transferred via mounting points onto the airframe and reemitted into the pressurized cabin.

A sparser series of high-frequency noise components, in comparison with Fig. 2, is observed in the pressurized cabin noise (see Fig. $3 a$ ), but an impressive series of low-frequency components is also reported in the spectrum (corresponding to fan shaft harmonics and the plunger pump harmonic).

The acoustic field of the pressurized cabin has become a subject to essential changes since high bypass engines were introduced [9].

Level of low-frequency components of the spectrum for superhigh bypass ratio engines is mainly defined by the conditions at the fan inlet (possibility of aerodynamic unbalance). These components will define the spectrum of power plant dynamic effect transferred via engine mounting attachment to airframe. This spectrum is reradiated into the cabin in the form of structural noise. An airframe typically possesses dozens of oscillation modes in the low-frequency spectrum part. The interaction of some of them with the perturbing action of the power plant via mounting attachment may lead to the generation of high-level low-frequency noise components in the pressurized cabin, including infrasound (Fig. 4).

On decreasing of fan noise, the low-frequency discrete components will determine the acoustical climate in the cabin. It was confirmed by new investiga- 


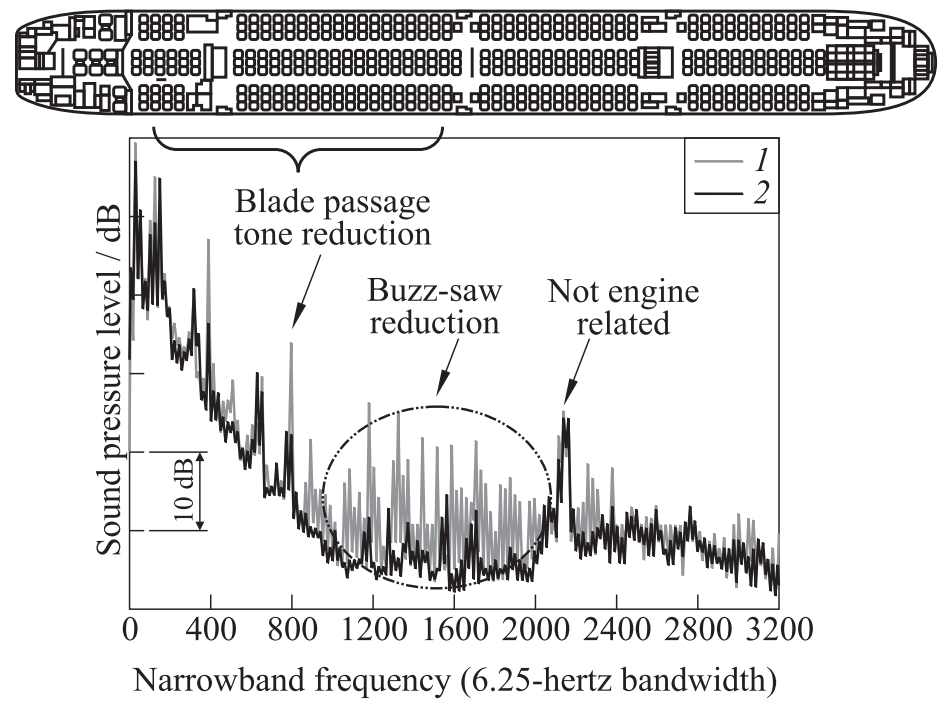

Figure 5 Forward cabin interior noise reduction as a result of acoustic smooth inlet: 1 - baseline and 2 - fully treated

tions on aircraft-demonstrator QTD-2 (Boeing-777 with engine GE-90-115B with bypass-ratio 8), where low-frequency components rise over 30-40 dB (Fig. 5) [10].

Decreasing of structure-borne noise will be an essential problem for providing comfortable conditions in the pressurized cabin, as its role increases with the introduction of high bypass ratio engines.

The present author believes finding a complex solution to the problem of both community's and cabin noises to be the most important challenge.

\section{THE SOLUTION}

A new decision concerning mounting of isolated engine is required in a wide range of frequencies, including an infrasound aspect.

Facilities for reduction engine vibration intensity and vibration transfer along structure come first by selecting of vibration protection for pressurized cabin and integration vibration protection units into engine mounting attachments seems to be the most effective.

But whatever vibration protection means (active or passive) are used to select the parameters of vibration isolation units, calculated model is required which is based on real dynamic characteristics of engines and airframe in mounting points. 


\subsection{Calculation Model}

A multicoupled model "engine-attachment-airframe" using the dynamical characteristics (dynamical compliance or elasticity, mechanical impedance or admittance, etc.) in attachment points was considered in [11].

Examples of successful application of such characteristics are known. One of the first times when such research was performed in current aviation (1967) was an investigation of DC-9 aircraft in the course of activities on eliminating reasons for increase of noise level in the cabin of the aircraft. But this analysis was confined to airframe and engine body impedance determination in one attachment point [12].

For the first time, a broad investigation of the set of dynamic compliances at the tail-end of airframe (the place of central engine location) and at the pods (the place of side engines location) and dynamical compliances of engine's body at the attachment points was carried out (1973) at the first specimens of the TU-154 aircraft with NK-8-2U engines.

The new procedure of estimation of engine dynamic impact on the airframe and of structural noise, created by engine vibration was suggested on the base of studying airframe and engine body dynamic characteristics and dynamic loading of engine struts.

This procedure was realized during the Program by research of dynamic compliances of TU-154M airframe and engine D-30KU body and also by testing transfer function of vibroacoustics conductivities of airframe design between impact points (engine mounting units) and the noise and vibration level check points (crew and passenger cabins). An analogy for this procedure was used in USA for a light airplane (Cessna 172) transmission model that includes engine mount dynamic characteristics at the attachment points and the acoustic response of selected cabin interior points and determined by impedance testing, but the engine was represented as a rigid body [13].

The multiconnected dynamic model of the system "engine-mount-airframe" (Fig. 6) can be studied by dividing it into independent subsystems, reaction forces being applied in the separation points. Then the differential equations for the displacements of separation points are written down where the generalized dynamic characteristics (for example, dynamic compliance) are used as factors of proportionality between dynamic displacement and forces.

Writing equations for displacements in separation points for each system, the following will be obtained:

$$
\left\{X_{E}\right\}=\left[C_{E S}\right] \cdot\left\{F_{E}\right\}+\left[C_{E}\right] \cdot\left\{R_{E}\right\} ; \quad\left\{X_{A}\right\}=\left[C_{A}\right] \cdot\left\{R_{A}\right\}
$$

where $\left[C_{E}\right]$ and $\left[C_{A}\right]$ are the matrices of dynamic compliances of engine and airframe in attachment points, respectively; $\left[C_{E S}\right]$ is the matrix of transition compliances of engine construction from perturbation force in engine elements 


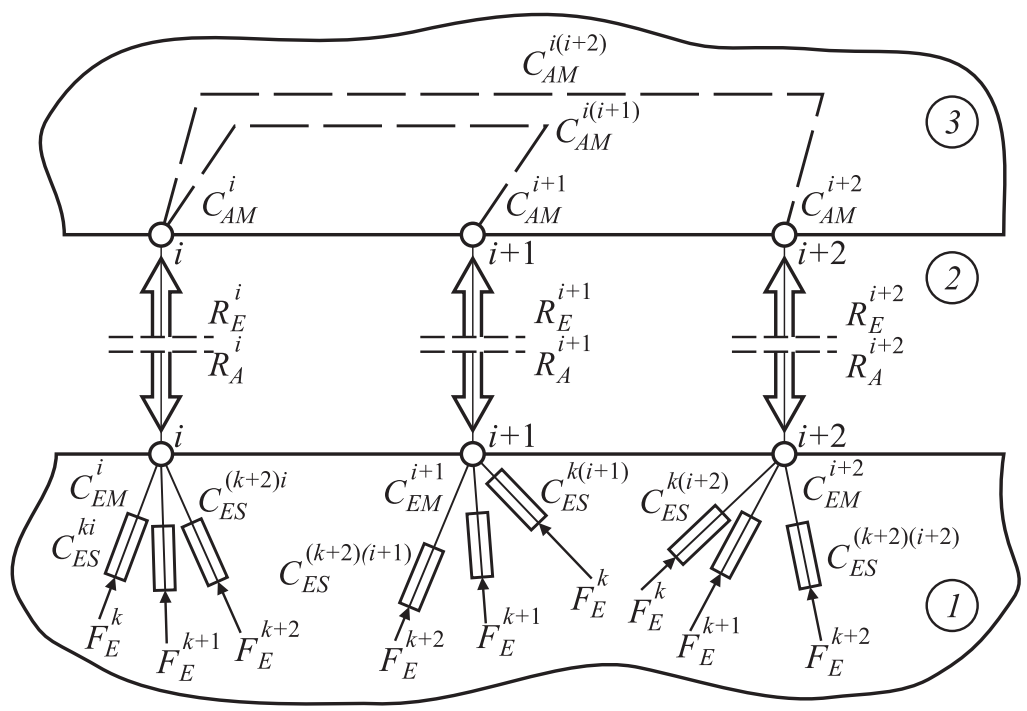

Figure 6 Separation scheme of full system "engine-mounting-airframe" on subsystems: 1 - engine; 2 - mounting; and 3 - airframe

to attachment points; $\left\{F_{E}\right\}$ is the matrix-vector of perturbation force in engine elements; $\left\{R_{E}\right\}$ and $\left\{R_{A}\right\}$ are the matrix-vectors of response forces in attachment points which describe engine and airframe dynamical behavior, respectively.

Engine as a rigid body has six degrees of freedom $(N=6)$. Six struts are used for engine mounting. These struts are combined into front and after engine mounting. Matrices $\left[C_{E}\right]$ and $\left[C_{A}\right]$ have dimension $N \times N$ where $N$ is the degree of freedom. $\left\{R_{E}\right\}$ and $\left\{R_{A}\right\}$ are the matrix vectors with $N$ lines. Matrix $\left[C_{E S}\right]$ depends on engine construction and have $K$ degrees of freedom and in the general case, this matrix has $N$ lines and $K$ columns. Matrix $\left\{F_{E}\right\}$ also has $K$ lines.

Taking into account that $\left\{X_{E}\right\}=\left\{X_{A}\right\}$ and reactions in these separation points are $\left\{R_{E}\right\}=-\left\{R_{A}\right\}$, the expression for estimation of level engine dynamical impact on airframe can be obtained:

$$
\left(\left[C_{E}\right]+\left[C_{A}\right]\right) \cdot\left\{R_{E}\right\}=\left[C_{E S}\right] \cdot\{F\} .
$$

In this convention, the expression for estimation of level engine dynamical impact on airframe becomes:

$$
\left\{R_{E}\right\}=\left(\left[C_{E}\right]+\left[C_{A}\right]\right)^{-1} \cdot\left[C_{E S}\right] \cdot\left\{F_{E}\right\} .
$$

Using the set of real dynamic compliances of the engines and airframes defined by experimental way, the limits of coupled vibrations of the "engine-attachmentairframe" system and the possibility of presentation of the system in the form of 
independent one-dimensional vectors (vibration conductor) as well were investigated.

The analysis of the obtained characteristics shows that the ratio of dynamic compliances (input and transient) differs considerably in the frequency range.

Taking into account this ratio, it is proposed to evaluate the possibility of ignoring the transient compliances, on the basis of comparison of the following matrix rates:

$$
L=\sqrt{\sum_{i, j=1}^{m}\left|C^{i j}\right|^{2}} ; \quad L^{*}=\sqrt{\sum_{i=1}^{m}\left|C^{i i}\right|^{2}}
$$

where $L$ and $L^{*}$ are the Euclidean rates of the total and diagonal structural matrices.

Then the value of $\alpha=\left(L-L^{*}\right) / L^{*}$ can be identified as a system coupling coefficient.

The made calculations convinced that at its sufficiently small values (less than $0.5 \%$ ), the "engine-mounting-airframe" complete system disintegrates to $m$ disconnected systems whose analysis is substantially simplified [14].

If the engine mounting attachments are dynamically independent, the equation for dynamic forces, acting from the engine upon the $i$ th coupling point, can be reduced to the following form:

$$
R_{e}^{i}(f)=\left[C_{e}^{i}(f)+C_{a}^{i}(f)\right]^{-1} \sum_{k=1}^{m} C_{e s}^{k i}(f) F_{e}^{k}(f)
$$

where the expression $\sum_{k=1}^{m} C_{e s}^{k i}(f) F_{e}^{k}(f)$ characterizes the engine vibration activity. Actually, this is the engine displacement at the attachment points (where the standard vibration pickups are usually installed), $C_{E M}$ and $C_{A M}$ are the engine and airframe casing structure dynamic compliances, respectively, at the attachment points; $C_{E S}$ is the transition compliances of engine structure between the points of force application and the attachment points; $F_{E}$ are the excitation forces within the engine components; $R_{E}$ are the reaction forces at the attachment points that characterize the dynamic influence of the engine upon the airframe.

The equation for the dynamic displacements $x_{E}^{i}$ of engine case in each $i$ th mount point can be transformed as follows:

$$
x_{E}^{i}(f)=\left[1-\frac{C_{E}^{i}(f)}{C_{E}^{i}(f)+C_{a}^{i}(f)}\right] \sum_{k=1}^{m} C_{E S}^{k i}(f) F_{E}^{k}(f) .
$$

The obtained expression allows to estimate expected dynamic impact level from basic sources (residual unbalance of engine's rotors) and other vibration activity 
elements installed on engine (hydraulic pump, gearbox, and perturbations in engine's gas-air flow duct).

Considering each $i$ th coupling of $m$ engine support couplings with the airframe structure to be a separate source of excitation, one can determine the sound pressure level $p^{n}$ that is generated at some point $n$ of the pressurised cabin as a sum of sound pressure values excited by each mentioned source:

$$
p^{n}(f)=\sum_{i=1}^{m} H_{A}^{i n}(f) R_{E}^{i}(f)
$$

where $H_{A}^{i n}(f)$ is the transfer function characterizing acoustic conductance of the airframe structure from the engine vibration exciting points (attachment points) to noise measurement locations; and $R_{E}^{i}(f)$ is the level of the engine dynamic effect upon the airframe structure at the $i$ th point of coupling. After that, the dB-noise evaluation can be written as

$$
L^{n i}(f)=L_{H_{A}}^{i n}(f)+20 \lg \left(C_{E S}^{i}(f)+C_{A S}^{i}(f)\right)^{-1} \frac{V_{E}^{i}(f)}{2 \pi f F_{\mathrm{sh}}^{i}(f)}
$$

where $L_{H_{A}}^{i n}(f)$ is the function of airframe structure acoustic conductance towards point $n$ if the impact is at the $i$ th attachment point $(\mathrm{dB}) ; V_{E}^{i}(f)$ is the engine casing vibration level near the $i$ th point of coupling $(\mathrm{cm} / \mathrm{s}) ; C_{E S}^{i}(f)$ and $C_{A S}^{i}(f)$ are the engine casing and airframe dynamic compliances at the $i$ th point of coupling $(\mathrm{cm} / \mathrm{kg}) ; f$ is the frequency $(\mathrm{Hz})$; and $F_{\mathrm{sh}}^{i}(f)$ is the force acting upon the airframe in the $i$ th attachment point $(\mathrm{kg})$.

Combining the separate sources of all engines, one obtains the total noise level of power plant vibration.

Reduction of the level of engine dynamic effect on the aircraft can be provided, for example, by building-in isolation units into the engine attachments, and then effectiveness $\left(\Delta L^{i}\right)$ of application of such units in case of dynamic independence of separate vibration vectors is defined for the $i$ th attachment from the following expression:

$$
\Delta L^{i}(f)=20 \lg \frac{1}{\eta_{i}}=20 \lg \left|\frac{C_{e}^{i}(f)+C_{a}^{i}(f)+C_{i s}^{i}}{C_{e}^{i}(f)+C_{a}^{i}(f)}\right|
$$

where

$$
\eta_{i}=\frac{R^{i}(f) \text { in case of vibroisol ating mount }}{R^{i}(f) \text { in case of rigid attachment }} .
$$

From the latter expression, one can define isolator compliance to ensure the required level of reduction $\left(\eta_{0}\right)$ of the forces transmitted to the aircraft:

$$
C_{i s}^{i} \geq \frac{1}{\eta_{0}} \sqrt{\left(\operatorname{Re} C_{e}^{i}+\operatorname{Re} C_{a}^{i}\right)^{2}+\left(\operatorname{Im} C_{e}^{i}+\operatorname{Im} C_{a}^{i}\right)^{2}\left(1-\eta_{0}^{2}\right)}-\left(\operatorname{Re} C_{e}^{i}+\operatorname{Re} C_{a}^{i}\right)
$$


where $\operatorname{Re} C_{e}^{i}, \operatorname{Re} C_{a}^{i}, \operatorname{Im} C_{e}^{i}$, and $\operatorname{Im} C_{a}^{i}$ are the real and imaginary components of dynamic compliances for the engine and aircraft, respectively, in the locations of the $i$ th attachment.

Different nature of structural dynamic behavior (the inertial one and the elastic one) convinces in necessity to know real dynamic characteristics of an engine and aircraft at mounting points to develop the effective isolating mountings of the engine.

\subsection{Experimental Data}

Several analytical models are considered together nowadays to predict the acoustic properties of the cabin. Although design models of the airframe, the pylon and the cabin take into account several thousands of freedom degrees, the engine is still considered to be a rigid body, its mass and moments of inertia only taken into account [15-18]. This is the due to an old tradition of successful flutter calculations, as the rigid-body engine model is still true in that range (low-frequency range, below $15 \mathrm{~Hz}$ ).

The dynamic characteristics enabled to make the dynamic model for an aviation gas-turbine engine more precise, especially in the rotor frequency range [19].

Such characteristics were determined for a number of bypass turbofan engines distinguished substantially both in thrust and bypass ratio $m$ (from $0.5-1.1$ to 2.5-5.0) and for airframes of trunk-route aircraft [20].

A well-known impedance testing technique was used: for the determination of these characteristics, the structures were excited by an electrodynamics shaker while the harmonic input force amplitude was constant and its frequency was varying automatically within the studied range (Figs. 7 and 8).

Compliance values of such subsystems as the engine and the airframe were determined by the method of test effect within 10-500-hertz frequency range.

Engine and airframe was subject to effect of a harmonic force being maintained constant within entire range investigated.

The investigated system linearity was verified by changing the effective force by several times; reciprocity principle was controlled by changing the locations of force application and response measurement. The information was processed with the use of a magnetic recorder unit, a 2-channel analyzer and an $X Y$ recorder.

The information was transmitted from the digital output of the analyzer to digital cassette recorder in order to create a databank. Then, it was loaded in a computer to perform necessary calculations, for example, to estimate the expected noise level due to engine vibration action.

In Fig. 9, the modifications of airframe frequency characteristics are presented. Below $50 \mathrm{~Hz}$, the fuselage is characterized by the row of resonances, being typical of beam-type airframe structure. In the range between 50 and 

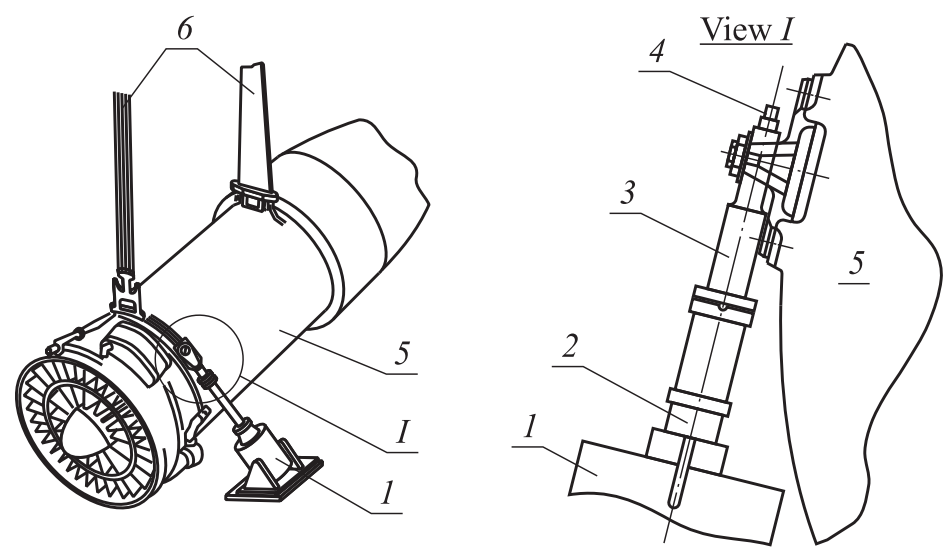

Figure 7 Testing of engine dynamic characteristics: 1 - electric dynamic shaker; 2 - sensor of force; 3 - testing strut; 4 - pickup; 5 - engine; and 6 - cords

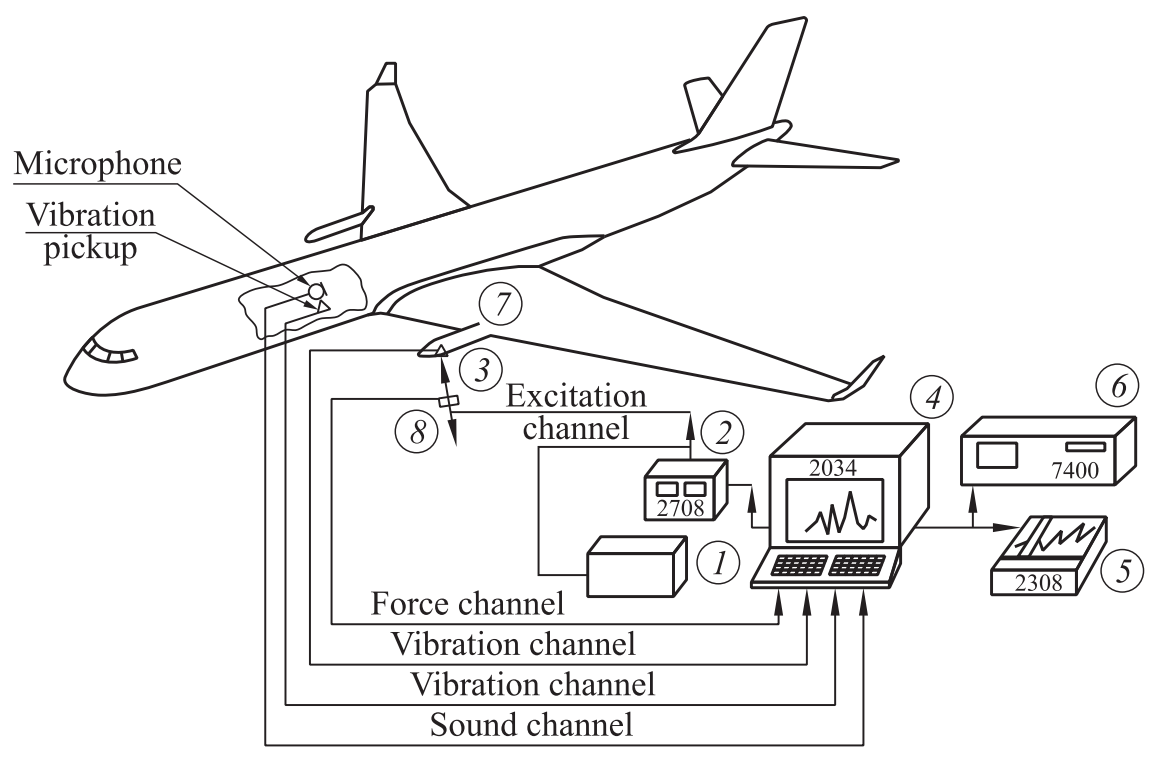

Figure 8 Testing of airframe dynamic characteristics: 1 - power amplifier; $2-$ sonic generator; 3 - shaker; 4 - two-channel analyzer; $5-X Y$-recorder; $6-$ digital cassette recorder; 7 - vibration pickup; and 8 - sensor of force 


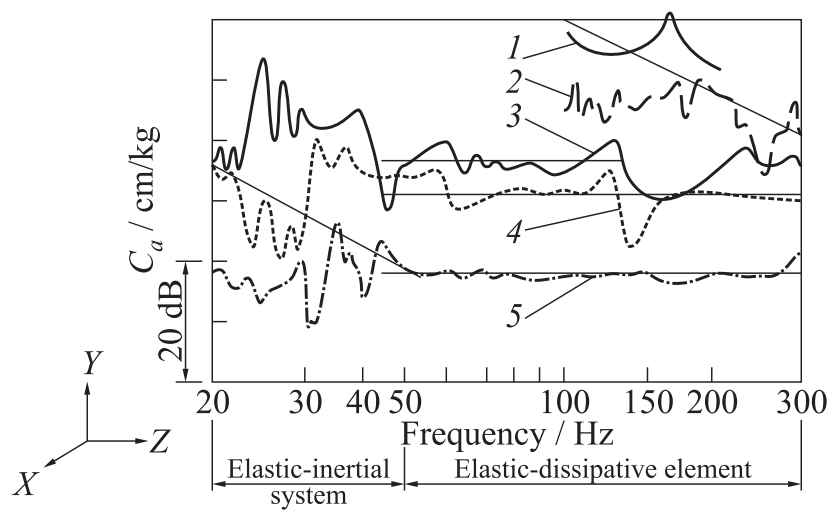

Figure 9 Dynamic compliance of airframe at the attachment points: 1 - DC-9; 2 TU-154M; 3 - compliance of airframe in the $Z$-direction; 4 - compliance of airframe in the $Y$-direction; and 5 - compliance of airframe in the $X$-direction (longitudinal)

$300 \mathrm{~Hz}$, the fuselage behaves as a hard elastic spring if the force is applied in the longitudinal direction $(X)$.

When the force acts in other directions $(Y, Z)$, the frequency range of fuselage elastic behavior shrinks down to $50-100 \mathrm{~Hz}$ and at the same time, the stiffness is decreased up to $5-10$ times.

The row of resonances, typical for separate elements of constructions (beams, frames, brackets, etc.), is observed above $100 \mathrm{~Hz}$ (curves 1-4).

As is evident from the presented data, the dynamic behavior of the airframe (at engine brackets attachment points) depends on the frequency range. Elastic airframe behavior accepted in many calculation models is limited by a rather narrow frequency range $(50-100 \mathrm{~Hz})$ which does not embrace the rotor frequency range of many-shaft engine.

Modifications of frequency characteristics of engine dynamic compliances are presented in Fig. 10.

The straight line in double-log scale ( $x$-axis — frequency, $y$-axis - compliance) with slope factor $12 \mathrm{~dB}$ per an octave corresponds to the function $C(f)=1 /\left(m(2 \pi f)^{2}\right),(C(f)$ is the dynamic compliance) which is a feature of a rigid body.

The straight line parallel to $x$-axis is a feature of an elastic element, whereas the one with the slope of $6 \mathrm{~dB}$ per an octave belongs to an elastic-dissipative element.

The analysis of obtained data makes it possible to divide the frequency range of investigation into three subranges characterized by certain dynamic behavior of the engine and, consequently, each of the mentioned ranges can be provided with its special mathematical model, simple and clear enough (see Fig. 10). 


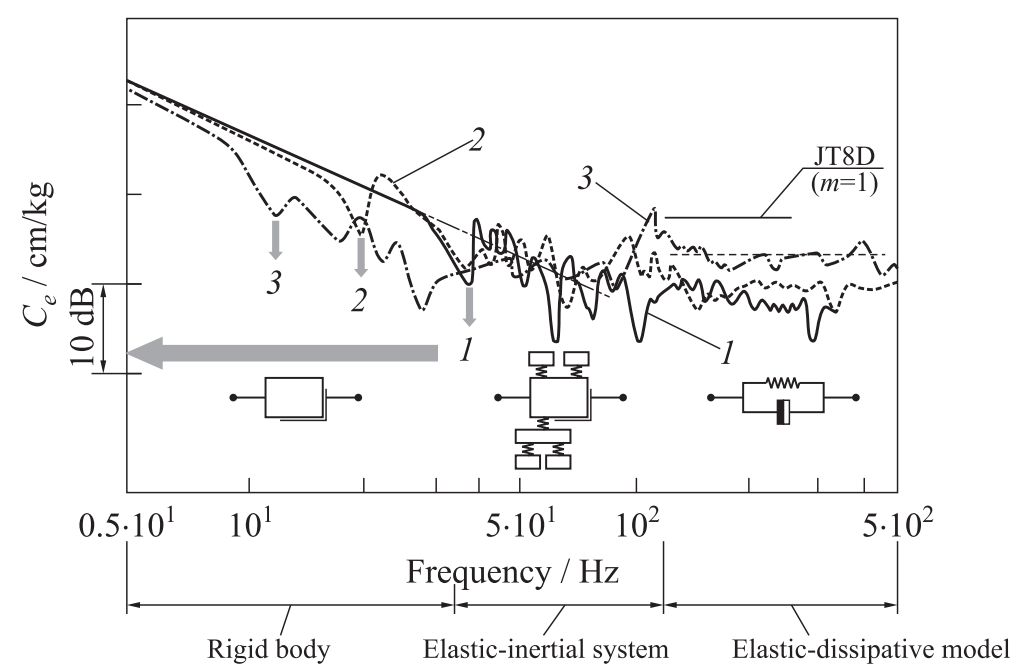

Figure 10 Dynamic compliances of engine body at attachment points: $1-m=1$; $2-2.5$; and $3-m=4.5$

Dynamic compliances of engine body at the attachment points has revealed that the body of engines with bypass ratio $m$ of $0.5-1.1$ corresponds to the rigid body model for frequencies below $40 \mathrm{~Hz}$, while for engines with bypass ratio of 2.5-4.5, the upper boundary of the rigid body model behavior is shifted to $20 \mathrm{~Hz}$.

It has been found out that at frequencies between $20-40$ and $120 \mathrm{~Hz}$ the engine body behaves as an elastic-inertial system with a large number of resonances of various damping degrees.

Within the frequency range $120-500 \mathrm{~Hz}$, the engine body corresponds to the model of elastic-dissipative element. The case of engine JT8D also corresponds to this model at the indicated frequency range [12].

The generalization of the performed investigations has revealed that the dynamic behavior of an advanced gas turbine engine body corresponds to the rigid body model for frequencies below $20-40 \mathrm{~Hz}$ depending on bypass ratio. If bypass ratio is increased up to estimated 8-12, one should expect that the upper boundary of rigid-body-like dynamic behavior of the engine does not exceed $10 \mathrm{~Hz}$.

Within a wide range of rotor frequencies, the dynamic behavior of engine body corresponds to the model of elastic-inertial system or to an elasticdissipative element. It differs substantially from the idealized rigid-body model of aircraft gas turbine engine both by the value of dynamic compliance module and by the type of dynamic behavior. 


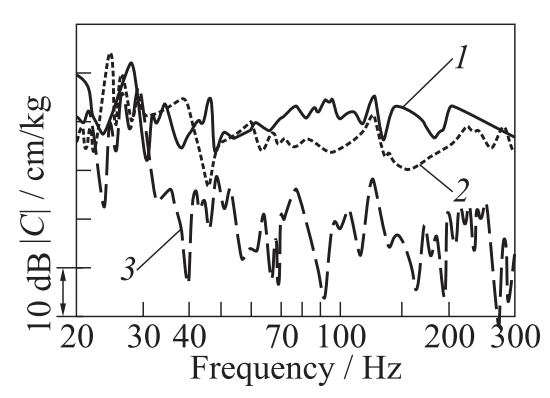

Figure 11 Comparison of input (1for the rear and 2 - for the front engine mounts) and transfer $(3$ - between the mounts) compliances

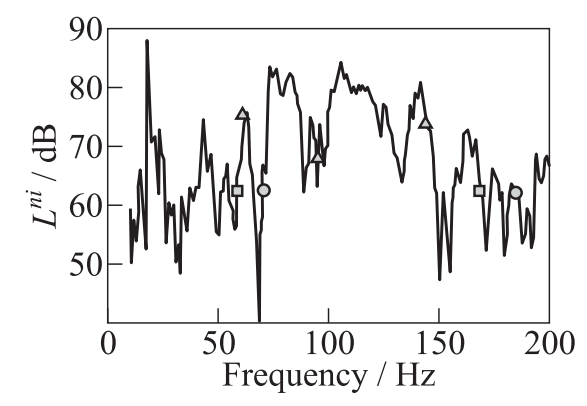

Figure 12 Vibroacoustic conductivity (marked points - cruise modes for different engines); excitation force $F_{\mathrm{sh}}^{i}=100 \mathrm{~N}$

The analysis of the features of dynamical compliances (input and transition compliances between the considered attachment points, Fig. 11) has shown the transition compliance to be $20 \mathrm{~dB}$ lower then the input compliances (at frequencies above $30 \mathrm{~Hz}$ ), within a broad frequency range corresponding to the rotor frequencies. Therefore, these attachment points can be considered as independent vibration conductor.

An example of vibroacoustical compliance transfer function between a point of impact (place of bracket attachment of engine) and a point in the cabin (place of noise monitoring) is presented in Fig. 12.

Transfer function characterizes the acoustic response of the cabin to the vibration impact of engine.

About 20 resonances have been observed in the frequency range between 20 and $200 \mathrm{~Hz}$, sound pressure difference reaching $30 \mathrm{~dB}$.

The points on the curve denote cruising rotation regimes for three engine types planned to be installed on the aircraft.

It should be noted that at the same acoustic impact level, the difference of the response of the cabin reaches $15 \mathrm{~dB}$ for different engines at cruising regimes.

The obtained characteristics and algorithms described above have allowed to calculate the expected noise due to vibration impact of engine.

Thus, high-level frequency components of noise generated by vibration impact from power plant can be observed in the cockpit. The calculation data have been confirmed by the results of experimental measurement (Fig. 13).

The comparison of the expected noise and the experimental data yields both a good convergence of fan rotor harmonic level and a possibility of high-intensity low-frequency components generation at the operation level of engine vibration.

On decreasing of fan noise, the low-frequency discrete components will determine the acoustical climate in the cabin. It was confirmed by new investi- 

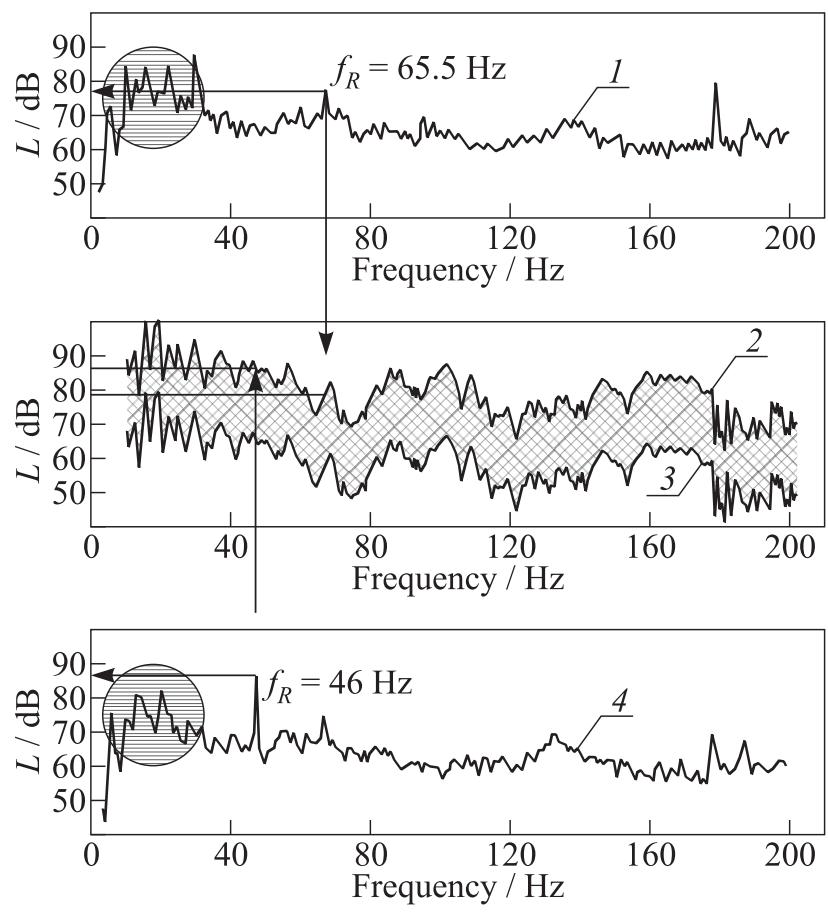

Figure 13 Structure-borne sound in cabin: 1 and 4 - experimental data, $V_{E}$ $=10 \mathrm{~mm} / \mathrm{s}$; and 2 and $3-$ prediction data, $V_{E}=10$ and $1 \mathrm{~mm} / \mathrm{s}$, respectively

gations on aircraft-demonstrator QTD-2 (Boeing-777 with engine GE-90-115B with bypass ratio 8 ) where low-frequency components rise over $30-40 \mathrm{~dB}$ (see Fig. 5) [10].

Hygienic, clinical-physiological, and experimental researches make it reasonable to claim the low-frequency noise (including 31-hertz octave band and, especially, infrasonic range within 8 - and 16-hertz octave bands) to be professionally harmful factor, influencing human health [21].

There are no obligatory international standards limiting internal noise in cabins of airplanes today. Execution of those or other conditions on noise (according to national standards) is a parameter of competitiveness of manufacturers or aircraft. The noise level in the cabin of pilots is fixed by the manufacturer in view of opinion of large airlines that covenant with trade union of pilots.

Therefore, the allowed infrasound levels at the places of operators, who perform the tasks of different mental and emotional tension, are proposed to be lowered. 
The necessity of new vibroisolation mounting relates with:

(i) extension of vibration spectrum of modern engines and its tendency to shift towards the low-frequency region;

(ii) insufficient efficiency of existing vibration protection, developed on the basis of out-of-date computation models, especially in the low-frequency region; and

(iii) change of dynamic characteristics of airframe and engine bodies at attachment points with the increase of engines bypass ratio.

\subsection{Concept of New Mount}

Necessary vibration protection level can be supplied by vibroisolation block with nonlinear elastic characteristics with quasi-zero stiffness work field for calculated force (for example, at cruise) [22].

Such device provides a large static elasticity of vibroisolation mounting and can function in wide range of dynamical forces and narrow displacement range.

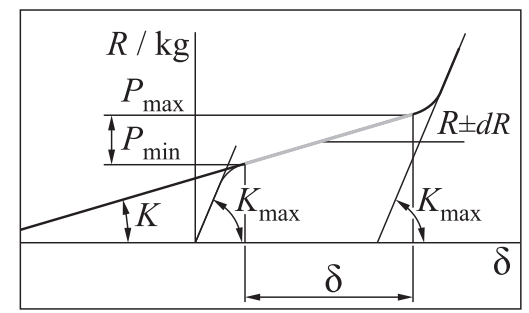

(a)

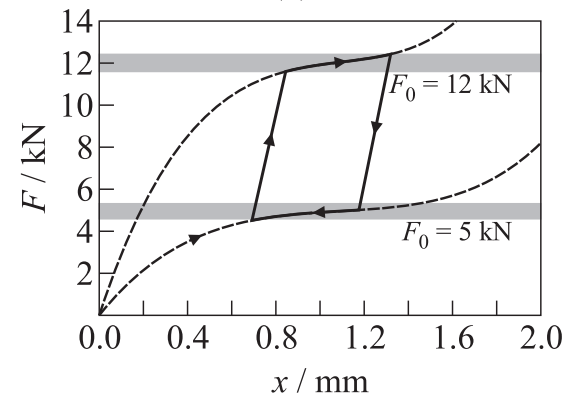

(b)

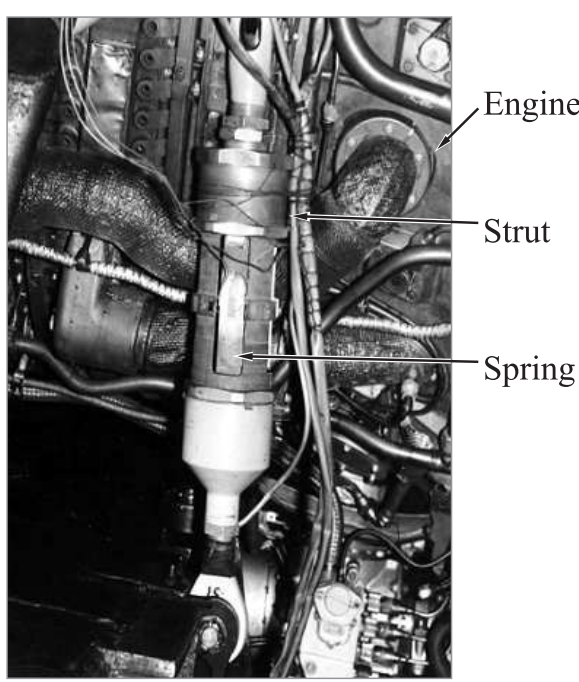

(c)

Figure 14 Elastic characteristic of element mount $(a)$, oriented mount on different static loads $(b)$, and example mount strut $(c)$ 


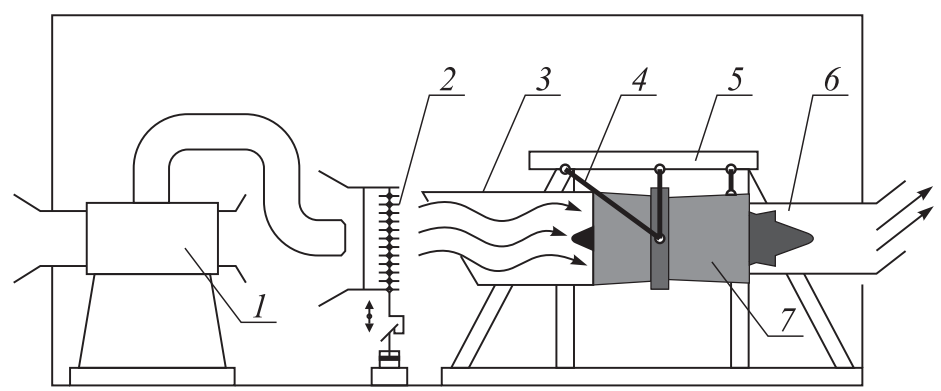

Figure 15 A special rig for experimental testing

All of these requirements satisfied using a vibroisolation mounting based on initially deformed elements with quasi-zero stiffness zone. It contains quasiunstable elements of different configurations with special nonidealities of shape and boundary conditions which determine an elastic characteristic: soft nonlinear with quasi-zero work field at calculated force.

In Fig. 14, the elastic characteristic of element mount $(a)$, oriented mount on different static loads $(b)$, and example mount strut $(c)$ are presented.

The computational investigations of low-frequency vibroisolation mounting dynamic model were carried out. Numerical investigations allowed to obtain a significant decreasing of oscillation amplitude in case of nonlinear elastic characteristics for all external dynamical force types [23, 24].

The suggested device was experimentally tested at special rig (Fig. 15). A flow-generation system (1) creates a quasi-homogeneous air flow which propagates through oscillation device (2). Then flow is directed to engine air-inlet (3). Engine (7) attached through mounting (4) to special beam (5) installed on massive fixed platform. A flow is taken off after engine through special device $(6)$.

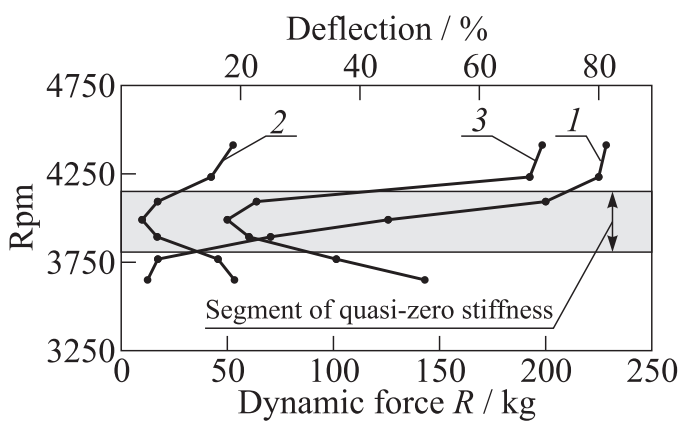

Figure 16 Experimental testing results 
In mounting (4), nonlinear elastic elements installed (see Fig. 14). A dynamical force level in engine mounting was registered.

In Fig. 16, an experimentally measured elastic characteristic of vibroisolation device (1), rotor component of dynamical force (2), and low-frequency component of dynamical force (3) are shown.

After experimental testing, it was shown that suggested mounting supplies a dynamical force level reduction on $12-14 \mathrm{~dB}$ in frequency range 8-80 Hz. Computational data are in qualitative and quantitative accordance with experimental data.

So, obtained results can be useful not only for new generation vibroisolation systems creation for aircraft engines but also for vibroisolation systems on vehicles (automobiles, trains, etc.), for building foundations designing (particularly, and for seismic districts), and for precision measuring devices vibroisolation.

\section{CONCLUDING REMARKS}

The vibrating spectrum of turbofan engines, especially extrahigh bypass ratio, essentially extends with shift in a low-frequency part of a spectrum, and will define a low-frequency part of a spectrum of structural noise in cabin.

A method of structural noise calculation, which takes into account real dynamic characteristics, such as dynamic compliance of engine's body and airframe has been suggested. The method allows to estimate changes of the acoustic field in the pressurized cabin for new aircraft generation.

Selecting power plant for airplanes of new generation should include developing a high-performance system of protection of crew and passengers for the maintenance of comfortable conditions and flight safety.

Long-term response test studies of engine body (with different bypass ratios) and airframe structure of aircraft have allowed:

- to specify design model of modern aircraft structures;

- to calculate expected structural noise on the new generation aircraft; and

- to offer the concept of new vibration isolation of the superhigh bypass ratio engine mounting.

\section{ACKNOWLEDGMENTS}

I am very grateful to the leading expert V. Vul for the help and valuable remarks and engineer I. Konovalov for his help at the paper design. 


\section{REFERENCES}

1. Uellenberg, S. 2004. Buzzsaw noise predictions for modern turbofans. AIAA Paper No. 2004-3000.

2. Philpot, M. G. 1970. The buss-saw noise generated by a high duty transonic compressor. ASME Paper No. 70-GT-54.

3. Morfey, C. L., and M. J. Fisher. 1970. Shock-wave radiation from supersonic ducted rotor. Aeronautical J. Roy. Aeronautical Soc. 74.

4. Pickett, G. F. 1972. Prediction of the spectral Content of Combination Tone Noise. J. Aircraft 9.

5. Stratford, B. S., and D. R. Newby. 1977. A new look at the generation of buss-saw noise. AIAA Paper No. 77-1343.

6. McAlpin, A., and M. Fisher. 2001. On the Prediction of buss-saw noise in aeroengine inlet ducts. J. Sound Vibration 248(1).

7. Shivashankara, B. 2002. Recent advances in aircraft noise reduction and future technology needs. Symposium (International) "Which technologies for future aircraft noise reduction?" Arcachon, France.

8. Baklanov, V., A. Zayakin, E. Orlenko, and S. Postnov. 2005. The calculation of structural noise in cabin for aircraft with high-by-pass ratio engines. AIAA Paper No. 2005-3034.

9. Baklanov, V., A. Zayakin, E. Orlenko, and S. Postnov. 2005. Expected vibroacoustical spectrum of high by-pass ratio power plant. In: Condition Monitoring. Cambridge: King's College.

10. Nesbitt, E., and Yu Jia. 2006. Quiet technology demonstrator 2 intake liner design and validation. AIAA Paper No. 2006-2458.

11. Baklanov, V.S., and V.M. Vul. 1992. Vibration isolation of aviation power plants taking into account real dynamic characteristics of engine and aircraft. 2nd Congress (International) on Recent Developments in Air- and Structure-Borne Sound and Vibration. USA: Auburn University.

12. Rubin, S., and F. A. Biehl. 1967. Mechanical impedance approach to engine vibration transmission into an aircraft fuselage. Aeronautic and Space Engineering and Manufacturing Meeting (SAE). Paper 670873.

13. Unruh, J.F. 1983. Procedure for evaluation of engine isolators for reduced structure-borne noise transmission. J. Aircraft 20(1):76-82.

14. Baklanov, V.S., and V.M. Vul. 1983. The influence of connecting fluctuations of complex dynamic systems on the evaluation of vibroisolation effectiveness. 10th Acoustic Conference. Moscow: Acoustic Institute. 65-68.

15. Auge, P., and A. Potiron. 1988. Modelisation dynamique simplifiee d'attaches de moteur d'avion en vue d'une conception optimisee. Materiaux Mecanique Electricinte. 426:27-29.

16. Johnescu, J. 2003. A sound practice: Test improves accuracy of acoustic aircraft cabin model. Aircraft Interiors 7(1):20-24.

17. Boeing Uses LMS SYSNOISE to Predict Acoustics of Aircraft Cabins. 2003. LMSnews. February 19-21. 
18. Hybrid simulation at airbus: A proven industrial process. 2003. LMSnews. February $22-23$.

19. Baklanov, V.S. 2002. Dynamic model of engine-mount-airframe system of trunkaircraft basing on results of impedance data tests at attachment points. 9th Congress (International) on Sound and Vibration. Orlando, Florida, USA.

20. Agafonov, V.K., V.S. Baklanov, V. M. Vul, V.I. Popkov, and A. V. Popov. 1990. The investigation of dynamic and vibroacoustic characteristics of aircraft and an engine by calibration test methods. 7th Aero-Acoustic Conference. Moscow: TsAGI. 141-44.

21. Alves-Pereira, M., M. Castelo Branko, J. Motylewski, A. Pedrosa, and N. Castelo Branko. 2001. Airflow-induced infrasound in commercial aircraft. INTER-NOISE 2001. The Hague, The Netherlands.

22. Baklanov, V. S., I. V. Golov, and S. S. Postnov. 2004. Vibroisolation of power plants for new generation airplanes with engines of high by-pass ratio. AIAA Paper No. 2004-2823.

23. Baklanov, V., S. Postnov, and A. Zayakin. 2006. The computational investigation of low-frequency vibroisolation mounting dynamic model. AIAA Paper No. 20062658.

24. Baklanov, V.S. 2007. Low-frequency vibroisolation mounting of power plants for new generation airplanes with engines of extra-high bypass ratio. J. Sound Vibration 308(3-5):709-20. 